\title{
SIMULATION ANALYSIS AND OPTIMIZATION OF DIE-CASTING FOR AUTOMOBILE STEERING SERVE SHELL
}

\author{
LI Jing1, XU Teng-Gang ${ }^{2}$, ZHU Jian-Jun ${ }^{3}$ \\ ${ }^{1}$ College of Mechanical Engineering, Shanghai University of Engineering Science \\ ${ }^{2}$ Collegeof Mechanical Engineering, Shanghai University of Engineering Science \\ ${ }^{3}$ Engineering Training Center, Shanghai University of Engineering Science
}

\begin{abstract}
The topic of issue was aimed at the problem of many of the defects of shrinkage and surface porosity of automobile steering valve shell in practical casting production, which can result the low passing of the products of the valve body, so the filling and solidification process of the die-casting were numerically simulated by using the Anycasting software. According to the simulation results, the causes of the problem were analyzed and measures for improvement were put forward. By means of setting up the additional cooling system in the mold, the simulation of improved scheme indicated that pores on the convex parts of binding sites disappeared, and islanding in thick wall area was significantly reduced. The improved process was verified by the actual production, the simulation results were in agreement with the production, and the yield of the product obviously increased.
\end{abstract}

Keywords: steering serve shell; die-casting; simulation analysis; defect optimization.

\section{INTRODUCTION}

With the development and progress of modern science and technology ${ }^{[1]}$, die-casting enterprises began to analysis technology for simulation analysis of die casting production before using CAE, position of defect prediction may appear in the castings and the degree of analysis of the causes of the defects, and targeted optimization, improve the qualified rate of casting products, reduce the number of test die mould modification.

This paper uses Anycasting software for a die casting enterprise production car steering servo shell casting simulation analysis of die casting, casting defect distribution prediction may arise, and to analyze its causes, and puts forward the corresponding improvement measures, provide the corresponding technical support for CAE die casting production enterprises $^{[2]}$.

\section{ANALYSISOF PARTS STRUCTURE AND}

\section{DEFECTS}

The vehicle steering servo steering housing is an important component in the assembly, for the protection of the fixed shell turbine and worm, it has high requirements of its strength and impact resistance, shown in Figure-1 with three-dimensional model steering servo shell for the car, the overall shape of product size is $190 \mathrm{~mm} * 148 \mathrm{~mm} * 109 \mathrm{~mm}$, the average wall thickness is $2.85 \mathrm{~mm}$, the maximum wall thickness is $15.78 \mathrm{~mm}$. For the production of casting blank car were randomly selected with steering servo shell castings were observed, section of thick wall can be seen more shrinkage porosity, as shown in Figure-2,the test piece was designated as the unqualified products.

\section{SIMULATION PRE-PROCESSING PARAMETERSETTING}

\subsection{Pre-processing Mesh Generation}

Using UG software to design a good turn of the servo shell CAD model for the STL file format, and imported into Any PRE Any casting software module ${ }^{[3]}$. Figure- 3 shows the steering servo shell cavity, gating system and exhaust system of the grid map. Owing to the irregular shape and uneven wall thickness of the servo case of the steering gear, in order to ensure the accuracy and efficiency of the calculation, the total number of grids generated by the method of non-uniform mesh generation is 10562790 .

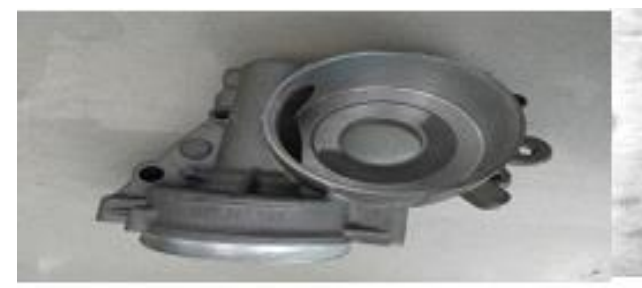

Fig-1: 3D model of steering servo shell

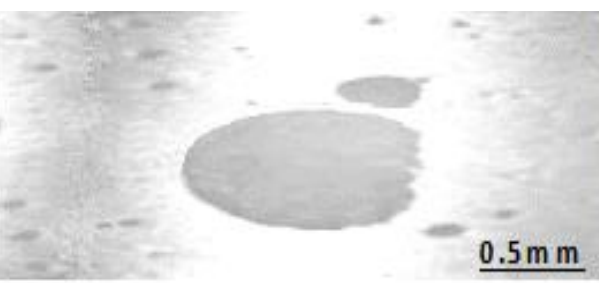

Fig-2: Actual shrinkage and pores defects of steering servo shell

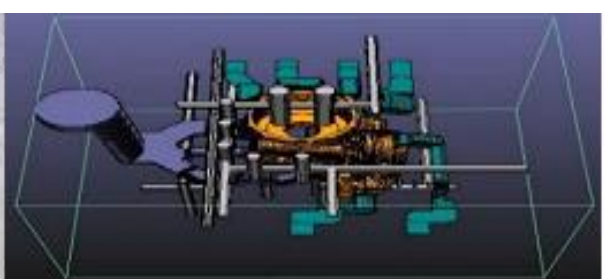

Fig-3: Finite element model of the original production plan 


\subsection{Selection and Setting of Parameters}

The casting material is ADC12 aluminum alloy with a liquidus temperature is $580^{\circ} \mathrm{C}$. The selection of die-casting process parameters is as follows: the casting environment temperature is $25^{\circ} \mathrm{C}$, the mold preheating temperature is $200^{\circ} \mathrm{C}$, the pouring temperature is $680^{\circ} \mathrm{C}$, and the injection speed is $300 \mathrm{~cm} / \mathrm{s}^{[4]}$.

According to the properties of die casting alloy, the actual casting conditions and structure characteristics of the casting, the following settings: the heat transfer coefficient of the heat transfer coefficient of the main cast from $0.6 \mathrm{Cal} / \mathrm{cm}^{2} * \mathrm{~S} *{ }^{\circ} \mathrm{C}$, the surface heat transfer coefficient and die casting of $0.05 \mathrm{Cal} / \mathrm{cm}^{2} * \mathrm{~S} *{ }^{\circ} \mathrm{C}$, the surface heat transfer coefficient of mold and air $0.001 \mathrm{Cal} / \mathrm{cm}^{2 *} \mathrm{~S} *{ }^{\circ} \mathrm{C}[5]$.

\section{SIMULATIONRESULTSANALYSIS}

\subsection{Simulation of Filling Process and Analysis of} Defects

In the casting simulation software Anycasting, the above parameters are set up before processing and solved ${ }^{[6]}$. Figure-4 shows the temperature distribution diagram of the metal liquid filling process after post-processing. We can find that the filling in front of liquid metal in the mold filling temperature is always maintained above the liquidus temperature of the alloy (liquidus temperature of ADC12 to $\left.580^{\circ} \mathrm{C}\right)^{[7]}$, simulation process parameters that the selected alloy is conducive to the flow of liquid pouring is insufficient or will not lead to the cold partition. It can be found that the metal flow is relatively smooth.

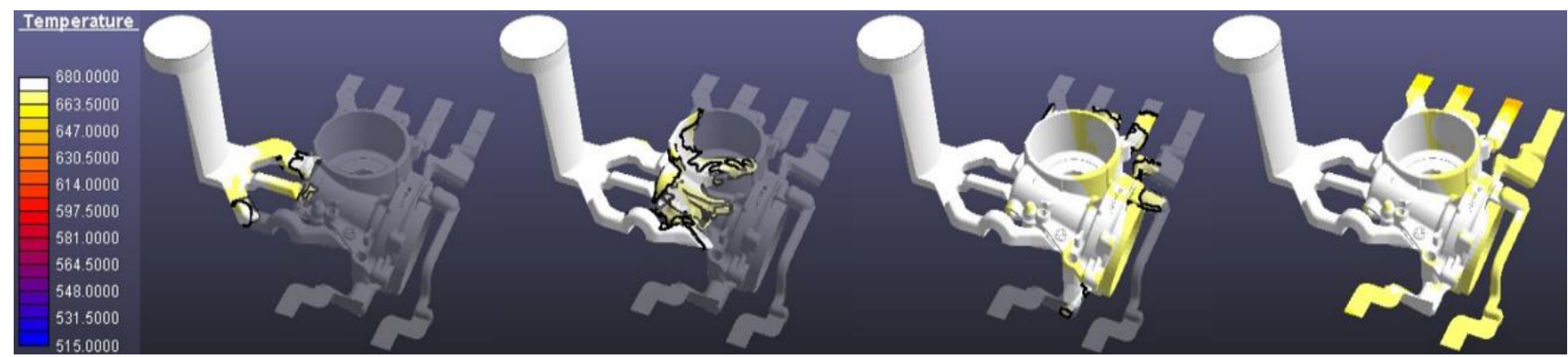

Comprehensive analysis does not need to adjust the filling mode of the casting.
(a) $\mathrm{t}=0.3758 \mathrm{~s}$
(b) $\mathrm{t}=0.3881 \mathrm{~s}$
(c) $\mathrm{t}=0.4155 \mathrm{~s}$
$(d) t=0.4213 \mathrm{~s}$

Fig-4: Temperature distribution during filling process of molten metal at different time

\subsection{Simulation and Defect Analysis of Solidification}

\section{Process}

Figure-5 is the solidification process of steering servo shell, from the solidification process of liquid metal can be seen: the liquid metal cavity is composed of cylindrical shell with thin wall thickness of stiffener joint parts gradually with solidification, solidification process, casting stiffener joint parts found later than the inner gate and overflow solidification. From the moment of the solidification process of $t=13.7411 \mathrm{~s}$ can be observed: reinforcement binding sites exist in two large isolated liquid region, but at the same time, gate already solidified, reinforcement binding site does not get to the outside of the liquid metal feeding, so the area is the main location of shrinkage defect. The analysis confirmed that the actual casting is shown in Figure 3. The reason for a large number of shrinkage and porosity defects is that:reinforcement parts with relatively thick, under the same cooling condition, need to transfer more than other areas of heat, resulting in the regional cooling solidification rate is slower than the surrounding and larger volume of isolated liquid region at the end of solidification, the gate has solidified under the condition of the isolated liquid phase can not be solidified free of the external metal liquid, forming a large number of scattered and small holes.

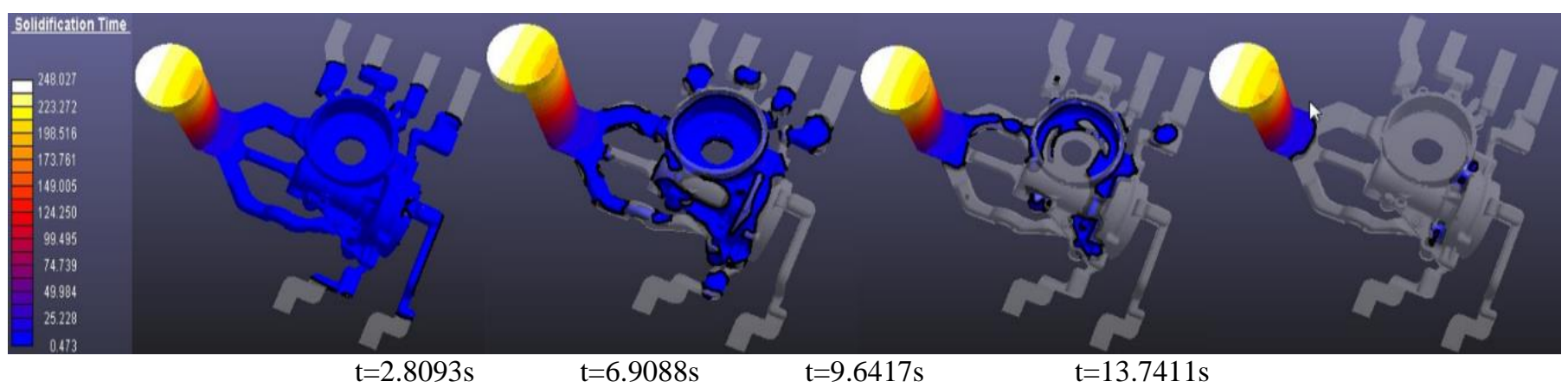

Fig-5: Solidification process of metal liquid at different time in the original scheme 


\subsection{Analysis and Optimization}

By simulating the filling and solidification process of the original die casting scheme, it is necessary to add a local cooling device on the die to improve the shrinkage porosity and shrinkage defects ${ }^{\left[{ }^{[}\right]}$.

\subsubsection{Cooling System Optimization}

According to the shrinkage the shrinkage defects in the casting reinforcement parts with increased cooling channels, to speed up the cooling rate, the temperature field of casting obtain reasonable in the cooling process, reduce the casting reinforcement with isolated liquid phase at site volume, in order to eliminate or reduce the shrinkage defects ${ }^{[9]}$.

\section{SIMULATION AND ANALYSIS AFTER OPTIMIZATION}

\subsection{Solidification Process}

Optimization of liquid metal solidification process as shown in Figure 7 under the program, the liquid metal from the steering servo shell casting of thin wall thickness gradually solidified, when the gate completely solidified, the casting reinforcement parts remain isolated liquid not solidified phase region, in the cooling effect of the cooling water channel points, compared with the original plan, volume of the isolated liquid region was significantly reduced. Although there are some defects exist, but this is inevitable in the process of die casting. As a whole, the possibility of reducing shrinkage defects is reduced obviously compared with the original scheme, which shows that the design of the optimization scheme is reasonable.

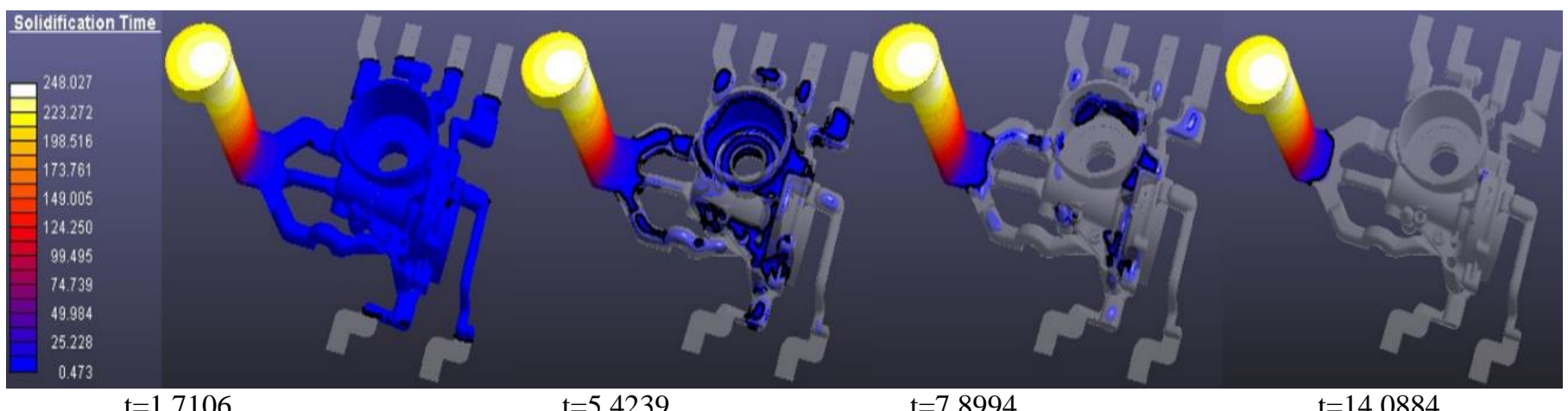

$\mathrm{t}=1.7106$

$\mathrm{t}=5.4239$

$t=7.8994$

$\mathrm{t}=14.0884$

Fig-6: solidification sequence of castings after optimization

\section{ACTUAL PRODUCTION VERIFIRATION}

The die casting machine is used to carry out the actual die casting production verification of the optimized die casting. The improved scheme produced by casting as shown in Figure 8, it can be seen from the figure: steering servo shell surface without obvious defects, combining the dissected casting reinforcement parts of profile zoomed in Figure 9 (a) optical micrographs for strengthening reinforced by the
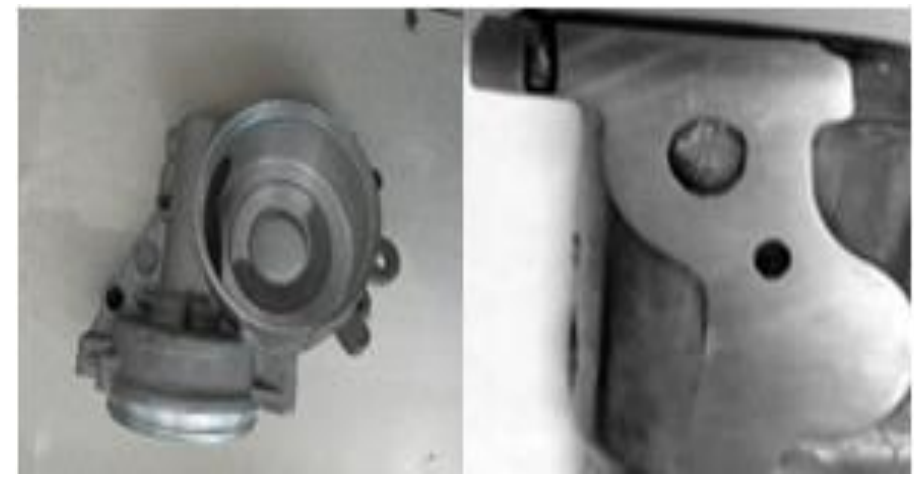

Fig-7: Actual casting under the optimized scheme. improved scheme produced by casting, only see some scattered and small shrinkage, compared to optical micrographs of the same section with the original plan of castings (Figure 9 (b)), servo shell casting reinforcement region with shrinkage porosity defect has been significantly improved, reached the actual production quality requirements $\left.{ }^{[} 10\right]$

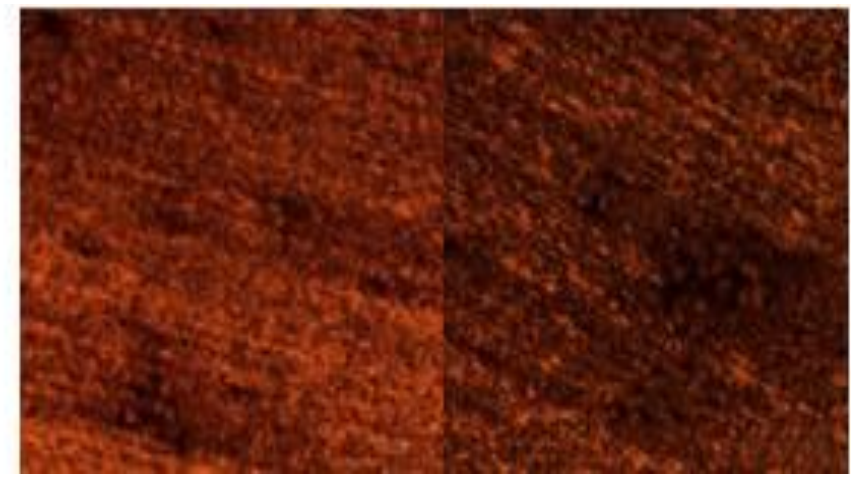

Fig-8 (a) Under the Fig.9 (b) Under the original scheme improved scheme 


\section{CONCLUDING REMARKS}

Using Anycasting die casting simulation software, the causes of shrinkage and porosity defects during the die casting of the steering case of steering gear were analyzed, and the die structure was optimized by adding cooling water channel. The following conclusions are drawn:

1) In the casting wall thickness increase the cooling water channel is conducive to make casting obtain reasonable temperature field in the cooling process, reduce the casting thickness of the isolated liquid phase volume, to eliminate or reduce the shrinkage shrinkage.

2) In the process of die casting production debugging, the CAE technology can be used to predict the defects of castings rapidly and effectively, and to analyze the causes of them, so as to provide the basis for modifying the die structure and optimizing the process.

\section{REFERENCES}

[1]. Huang Xiaofeng, XieRui, TianZaiyou, etal. Development status and Prospect of die casting technology [J]. New technology and new process, 2008 (7):50 - 55.

[2]. Yang Liwei. Present situation and future development trend of casting CAE technology [J]. Emphasis on technology, 2015 (3): 62 - 66.

[3]. Zhen Xiao Zhen, Li Zhi Li, Fu Hui, etal. Optimal design of ultrasonic cutter based on finite element model [J]. Piezoelectric and acoustooptic, 2015, 37 (6): 1083 - 1087.

[4]. Chen Hongkai, Song Yunmei. Simulation of J finite element numerical form Chongqing Hechuan mill dangerous rock mass[J]. Journal of Chongqing Normal University (NATURAL SCIENCE EDITION), 2016 (1): 36 - 39.

[5]. Niu Po, Yang Ling, Zhang Ting Ting, etal. Finite element analysis of rotary tiller used in micro tillage machines based on ANSYS Workbench. Journal of Southwestern University (NATURAL SCIENCE EDITION), 2015, 37 (12): 162 - 167. [6]. Li Dongze, GuoXiaonan, Yan Zhuo Cheng, etal. Abaqus based finite element analysis of PDMS [J]. Electronic components and materials, 2015 (11): 57 - 60.

[7]. Siku, Chen Shenggui bell, Huanhuan. Finite element simulation of laser transmission welding of polycarbonate [J]. Numerical laser journal, 2015 (6): 104 - 107.

[8]. Zhang Wenshan, Liu Shuqin. Design of drive motor of magnetic levitation artificial heart pump combined with magnetic circuit method and finite element method [J]. Electrical machinery and control applications, 2016, 43 (4): 71-76.

[9]. Song Bo. Numerical simulation analysis of die casting of aluminum alloy wheel. [J]. Casting technology, 2014 (10): 2352 - 2354.

[10]. Jiang Zheng, XueKemin. Numerical simulation analysis of aluminum alloy die casting technology [J]. Precision forming engineering, 2012 (2): 42 - 45. 